\title{
Change in pulse rate with Enviro Chip and dummy chip fixed on radiation emitting devices like mobile phones/computers/laptops of users-A double blind crossover study
}

\author{
Ajay Poddar ${ }^{1}$, Sunita Rana ${ }^{1}$, Vanita Mittal ${ }^{2}$, Saroj Kumar Sabath ${ }^{3}$, Danish Mahmood ${ }^{4}$ \\ ${ }^{1}$ Syenergy Environics Limited, New Delhi, India \\ ${ }^{2}$ Head of Department, Emergency, Max Hospital, New Delhi, India \\ ${ }^{3}$ Max Super Specialty Hospital, New Delhi, India \\ ${ }^{4}$ Max House, 1, Dr. Jha Marg, Okhla Phase III, New Delhi, India \\ Email: ajay@environics.co.in, research@environics.co.in, drvanitamittal@gmail.com, saroj.kumar@maxhealthcare.com, \\ Danish.Mahmood@,neemanasia.com
}

Received 10 June 2013; revised 10 July 2013; accepted 20 July 2013

Copyright (C) 2013 Ajay Poddar et al. This is an open access article distributed under the Creative Commons Attribution License, which permits unrestricted use, distribution, and reproduction in any medium, provided the original work is properly cited.

\begin{abstract}
Use of Electronic gadgets such as mobile phones, computers/laptops constitutes an integral part of human day-to-day activity in offices and businesses. Therefore, their use cannot be stopped. These electronic gadgets emit electromagnetic radiations, which are believed to be hazardous to human health. World Health Organization/International Agency for Research on Cancer has classified radiofrequency electromagnetic fields as possibly carcinogenic to humans (Group B). The Enviro Chip developed by Synergy Environics, India, is a radiation harmonizing chip which when fixed on electronic gadgets at specific locations claims to reduce stress level by reducing the pulse rate of users which may also result in improvement of other health parameters. In this study, we have tested the ability of the Enviro Chip to reduce pulse rate of people who may have developed high pulse rate due to prolonged use of electronic gadgets. This was the double blind crossover study conducted in 205 healthy volunteers having an average pulse rate of above 82 per Minute at Max Healthcare India. The primary objective of the study was to evaluate and compare the change in pulse rate over 14 measurements with the use of both the Enviro Chip and a
\end{abstract}

\footnotetext{
*The authors of the study declare no conflict of interest.

Author's contribution: Ajay Poddar: Funding, research idea, hypothesis design, study design; Sunita Rana: Literature search, hypotheses and study design; Dr. Vanita Mittal: Principal Investigator; Dr. Saroj Kumar Sabath: Co-investigator; Danish Mahmood: Literature search and manuscript writing.
}

Dummy chip from average pulse rate at baseline without the Placebo effect. The secondary objective was to evaluate the change in pulse rate gender-wise. Data analysis was done using Wilcoxon Sign Rank test. The study demonstrated statistical significant reduction in pulse rate over 14 measurements with the use of Enviro Chip in both male and female healthy volunteers $(\mathbf{p}<\mathbf{0 . 0 0 1})$. Enviro Chip has a potential to reduce pulse rate of those people who have higher pulse rate due to prolonged use of high-end electronic gadgets. The testing was done on people using mobile phones and monitors/computers for long hours.

Keywords: Electromagnetic Radiations; Pulse Rate; Enviro Chips; Radiation Harmonization; Mobile Phones

\section{INTRODUCTION}

Over the last decade, India has witnessed an exponential rise in the use of mobile phones, personal computers, and laptops not only in urban metros but also in remote villages. Studies and published data indicate that electronic devices emit electromagnetic radiation (EMR) of varying magnitude and strength, which have thermal and nonthermal effects on human health. This impact is more visible in India due to densely populated townships and cities [1-5]. Non-thermal effects could affect cell membrane permeability, unfolding of proteins (conformational changes in protein structures), stimulation of thyroid, reduced neutrophil, complement activity, increased lymphoblastoid transformation of lymphocytes, and 
abnormalities in the precursors in bone marrow, and increased susceptibility to bacterial infection [6].

There has been a considerable debate over the impact of EMR on human health. In 2004, World Health Organization had reported electromagnetic hypersensitivity in individuals exposed to EMR wherein individuals experienced adverse health effects such as headache, thought processing difficulties, memory impairment, heart palpitations, sleep disorder, general malaise, blurred vision, weakness, dizziness, chest discomfort, muscle pain, tinnitus, fatigue, nausea, night sweats, restless legs, and paraesthesia while using or being in vicinity of devices emitting electric, magnetic, or electromagnetic fields [7, 8]. Various literatures providing evidences on adverse effects of EMR on human health which have been summarized in Table 1. Recently, scientists from 14 countries at World Health Organization/International Agency for Research on Cancer met in Lyon, France, 2011, classified radiofrequency electromagnetic fields as possibly carcinogenic to humans (Group 2B) [9]. During recent times, an exponential rise in the users of modern electronic gadgets such as Mobile Phones, Laptops, and Desktop PC's has been reported. Efforts have been made by organizations and individuals to develop devices with a potential to stop or at least reduce adverse radiation effects from electronic devices. At present, several devices are available which claim to either block or absorb the radiation, but as per the authors, radiations cannot be blocked for more than a few seconds or minutes and if blocked, could lead to weaker signal transmission result- ing in poor quality of voice/text/data from the device. Also, it does not make sense to spend billions to generate signals only to try and reduce them. In 1991, a scientific report showed that mouse cells exposed to regular $60 \mathrm{~Hz}$ EMF (electric and magnetic field) had double the activity of ornithine decarboxylase (ODC), an enzyme critical to deoxyribonucleic acid but the ODC activity was not increased in mouse cell exposed to randomly varying EMF between $55 \mathrm{~Hz}$ to $65 \mathrm{~Hz}$ at interval of less than one second [10]. Hence, the change of the nature of EMF from regular field to random field renders the EMF non bioeffective considerably reducing harm from their exposure and the first time indicates the development of radiation protective devices [11].

The Enviro Chip (Figure 1) is a radiation harmonizing chip manufactured by Environics and is to be fixed on Mobile Phones, Laptops, and Desktop PC's. This chip claims to improve health parameters by reducing adverse radiation effects. The chip when fixed at a certain location of the electronic devices works by changing the nature of emitted EMR from regular field to random field rendering them non bio-effective.

\section{METHODS}

\section{Study Design and Participants}

In this study, the efficacy of radiation harmonizing Enviro chip has been evaluated in the healthcare environment considering pulse rate as one of the clinical parameters.

Table 1. Studies showing adverse health effects of EMR-radiation.

\begin{tabular}{|c|c|c|}
\hline S. No & Studies on Adverse radiation effects & References \\
\hline 1. & $\begin{array}{l}\text { - } \uparrow^{\text {sed }} \text { risk of acoustic neuroma by over } 4.2 \text { times and by } 2 \text { times for the other side of the head with use of mobile } \\
\text { phone for } 1 \mathrm{~h} \text { per day for over } 10 \text { years }\end{array}$ & [1] \\
\hline 2. & - $\quad \uparrow^{\text {sed }}$ DNA damage in brain cells of rats exposed to cellphones radiation & [18] \\
\hline 3. & $\begin{array}{l}\text { - } \uparrow^{\text {sed }} \text { risk of brain tumors in people who used phones for } \geq 10 \text { years in } 3 \text { independent studies } \\
\text { - } \quad 2 \text { studies correlated brain tumor's location and the side of the head where people held the phone most } \\
\text { - } 1 \text { study suggested the greatest risk of brain tumors is in people who began using the phones before age of } 20 \text { years } \\
\text { - } \quad \text { The use of cell phones before age of } 20 \text { years } \uparrow^{\text {sed }} \text { the risk of brain tumors by } 5.2 \text {, compared to } 1.4 \text { for all ages }\end{array}$ & [19] \\
\hline 4. & - $\quad$ REFLEX Study reported that radiation at some cell phone levels damages DNA & {$[20]$} \\
\hline 5. & $\begin{array}{l}\text { - A Saudi Arabian study found a relationship between headache, fatigue, dizziness, tension, and sleep disturbances } \\
\text { in subjects exposed to mobile phones emissions }\end{array}$ & [21] \\
\hline 6. & $\begin{array}{l}\text { - The most commonly reported symptoms of EMR absorption in humans included sleep disorders, headaches, } \\
\text { nervousness, distress, fatigue, and attention deficits } \\
\text { Other common symptoms were redness, tingling and burning sensations of skins, tiredness, dizziness, nausea, } \\
\text { heart palpitation, and imbalances of digestive systems }\end{array}$ & {$[22]$} \\
\hline 7. & $\begin{array}{l}\text { - } \uparrow^{\text {sed }} \text { susceptibility in some individuals to developing arrhythmia, heart palpitations, heart flutter, or rapid heart- } \\
\text { beat and/or vasovagal symptoms such as dizziness, nausea, profuse sweating and syncope on exposure to mi- } \\
\text { crowave radiation }\end{array}$ & {$[22]$} \\
\hline 8. & $\begin{array}{l}\text { - Risk for brain tumors } \uparrow^{\text {sed }} \text { significantly for people who used mobiles more intensely and for more years. } \\
\text { - } \uparrow^{\text {sed }} \text { risk of brain cancer on the same side as one held the phone, but not on the other side } \\
\text { - } \uparrow^{\text {sed }} \text { risk of acoustic neurinoma, a benign nerve sheath tumor by over } 30 \% \text {, causing permanent deafness if not } \\
\text { removed }\end{array}$ & {$[23]$} \\
\hline 9. & - $\quad \uparrow^{\mathrm{sed}}$ risk of glioma or brain tumors with overuse of mobile phones & [23] \\
\hline
\end{tabular}




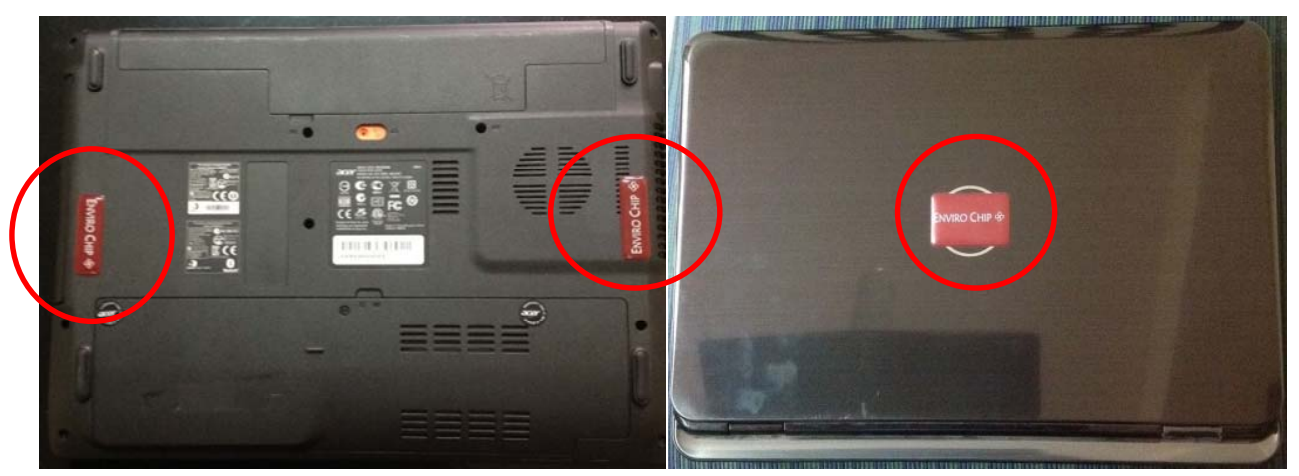

(a)

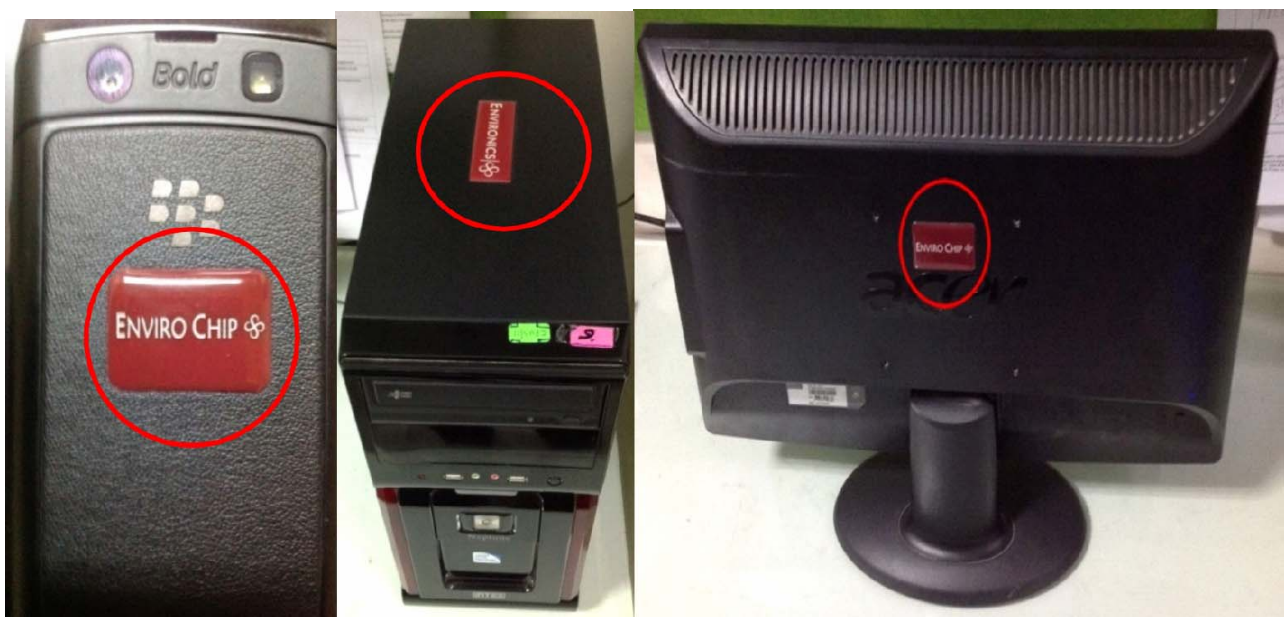

(b)

Figure 1. Position of Enviro Chip on laptop (back and front), mobile and CPU of computer. (a) Enviro Chip (in red circle) on the back and front of Laptop; (b) Enviro Chip on mobiles, central processing unit (CPU) and monitors of computer.

This was a double-blind crossover study conducted at Max Super Speciality Hospital, New Delhi, India (Figure 2). It was approved by the ethics committee of the Max Healthcare. It has also been registered with the relevant National Body (Clinical Trial Registry of India). Two hundred and five subjects provided their consent to the study but the final analysis was done on 155 subjects since 50 subjects failed to provide the required number of pulse readings due to rejection of abnormal readings from the analysis. Abnormal pulse reading was defined as $>$ or $<10 \%$ from the mean data determined after recording of all the data. Subjects who used mobile phones/laptops/desktops for at least four to five hours per eight hour duty day, and had the pulse rate $>82 / \mathrm{min}$ were included in the study.

At the initiation of the study, three pulse readings (first reading in the morning, second reading in the evening, and third reading in the morning on the next day) were obtained from all 205 subjects and average of three readings was calculated. This average reading was considered as the baseline reading. First, the dummy chip was fixed on electronic gadgets (Figure 1) such as mobile phones/ computers/laptops of volunteers and a minimum of 14 pulse readings (two times a day; first reading in the morning and second reading in the evening) were obtained for each participant. Thereafter, Enviro Chip was fixed and a minimum of 14 readings were obtained in the similar manner. No data was recorded immediately after eating, drinking tea/coffee, smoking, and excessive stress.

Since minimum 14 readings were required for the analysis, hence for those participants who were not present continuously during the study, their subsequent readings were taken when they joined the office so that minimum 14 readings required for the analysis could be completed.

All pulse readings were recorded and entered in the appropriately designed case report forms by the study investigator. After fixing the Enviro Chip and the Dummy Chip on mobile phones/laptops/desktops, average of 14 pulse readings was recorded and compared with pulse reading at baseline using Wilcoxon Sign Rank test. Additional analysis was done gender-wise. All readings were recorded as mean \pm standard deviation (SD) and signifi- 


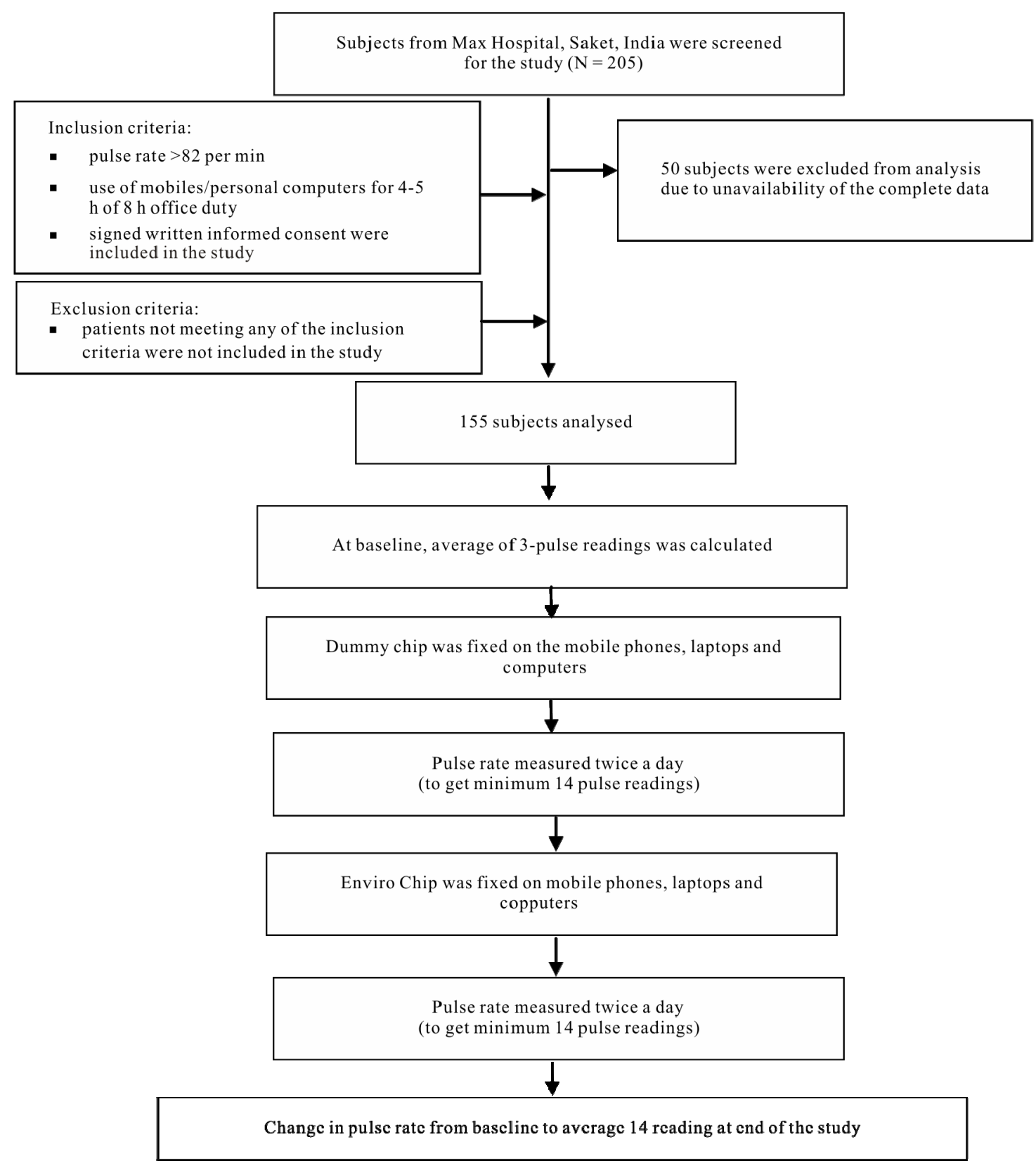

Figure 2. Study flow chart.

cance was calculated at the level of five percent.

\section{RESULTS}

A total of 155 healthy volunteers (males: 106, females: $49)$ with the pulse rate $>82 /$ min were assessed in the study. After installation of the Enviro Chip on electronic gadgets, the average pulse rate significantly decreased from $87 / \mathrm{min}$ (at baseline) to $83 / \mathrm{min}$ at end of the study $(\mathrm{p}<0.0001)$. A statistical $(\mathrm{p}<0.05)$ significant percentage change was observed with the use of EnviroChip. The percentage reduction of pulse rate from baseline to average of 14 readings is shown in Figure 3. However, no significant change in the pulse rate was observed after use of the Dummy chip. Additional analyses were carried out gender-wise to investigate the effect of Enviro Chip on pulse rate in healthy males and females. In both males and females, analysis of 14 readings showed statistically significant $(\mathrm{p}<0.001)$ reduction in the pulse rate. A comparison of the pulse rate reading between dummy chip and EnviroChip is presented in Table 2.

\section{DISCUSSION}

The present study was a double-blind, non-randomized crossover study which compared the efficacy of Enviro 
Table 2. Comparison of pulse rate reading between dummy chip and Enviro Chip at end of study.

\begin{tabular}{|c|c|c|c|c|c|c|c|c|}
\hline \multirow{3}{*}{ Study Parameters } & \multicolumn{8}{|c|}{ Pulse/minute (mean [SD]) } \\
\hline & \multicolumn{4}{|c|}{ Dummy Chip } & \multicolumn{4}{|c|}{ Enviro Chip } \\
\hline & At baseline & $\begin{array}{c}\text { Average of } \\
\text { 14-pulse } \\
\text { read }\end{array}$ & $\begin{array}{c}\text { Change in } \\
\text { Pulse [1] }\end{array}$ & $\begin{array}{c}\text { Percentage } \\
\text { Change in } \\
\text { Pulse [2] }\end{array}$ & Baseline & $\begin{array}{c}\text { Average of } \\
\text { 14-pulse } \\
\text { read }\end{array}$ & $\begin{array}{c}\text { Change in } \\
\text { Pulse [1] }\end{array}$ & $\begin{array}{c}\text { Percentage } \\
\text { Change in } \\
\text { Pulse [2] }\end{array}$ \\
\hline Pulse/min & $87.0(3.6)$ & $88.1(2.6)$ & $0.1(2.0)$ & $0.1(2.3)$ & $87.0(3.6)$ & $83.0(3.0)$ & $-4.1(1.3)^{*}$ & $-4.6(1.4)$ \\
\hline \multicolumn{9}{|c|}{ Gender } \\
\hline Females & $87.6(4.2)$ & $87.2(3.2)$ & $-0.3(2.2)$ & $-0.3(2.5)$ & $87.6(4.2)$ & $83.7(3.5)$ & $-3.9(1.5)^{*}$ & $-4.4(1.5)$ \\
\hline Males & $86.8(3.2)$ & $87.0(2.4)$ & $0.2(1.9)$ & $0.3(2.2)$ & $86.8(3.2)$ & $82.6(2.7)$ & $-4.1(1.3)^{*}$ & $-4.7(1.4)$ \\
\hline
\end{tabular}

[1]: change in pulse denotes Average 14 pulse reading - Baseline pulse reading; [2]: Average \% change calculated by formula, $\%$ change $=[($ Average of 14 readings $)-($ Average of baseline $) /($ Average of baseline $)]$. . Significance level at $\mathrm{p}<0.05 \%$.

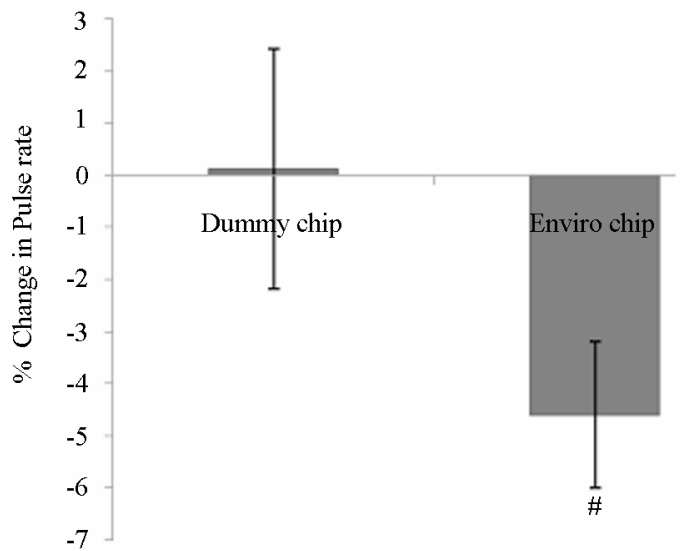

Figure 3. Percentage change in the pulse rate from base line.

Chip with the Dummy chip by evaluating the change in pulse rate over 14 measurements

Several experiments and empirical observations and evidences establish that radiation emitted from mobile phones/laptops/personal computers pose serious threats to human health. Seeing that their use has increased considerably, the dimensions of the problem are more pronounced as the actual effects will be manifest after many years. Computers and laptops have been reported to operate at frequency range of $1000-3600 \mathrm{MHz}$, and $\mathrm{Wi}-\mathrm{Fi}$ systems and some cordless phones operate at $2450 \mathrm{MHz}$. The effects of radiation absorption by the human body vary in magnitude with both the frequency of electromotive field and types of tissues exposed and absorption of radiation has been reported to be more in tissues containing high water content e.g. cardiac tissues than tissues with low water content e.g. adipose tissues. Therefore, heart and blood are specifically vulnerable to adverse radiation effects from electronic gadgets emitting radiofrequency waves [12]. However, there remains dearth of evidence establishing quantitative relationships between exposures to various forms of non-ionizing radiation and pathological implications on health of human beings.
Pulse rate or heart rate has been regarded as an important predictor of human health and high pulse rate is regarded as not good for health [13-16] and any deviation from normal values is indicative of pathophysiological changes in human body, and usually noticed during diseased condition and periods of excitement and stress. The resting heart rate/pulse rate in adults usually ranges from 60 to 80 beats per minute. Increase in the pulse rate suggests that heart is beating faster and heart is putting in an extra force to circulate blood into arteries. On the other hand, low pulse rate (within the normal range) is regarded as an indicator of healthy heart and is pumping blood into the arteries with ease.

In 2008, Andrzejak et al. demonstrated that during a 20-minute telephone call with phone working on a Global System for Mobile communications, the standard deviation of human heart rate in 32 healthy subjects increased from 74 pulse per minute (without cellphones) to 92 pulse per minute [17].

In 2010, Havas et al. showed causal relationship between pulse, $100 \mathrm{~Hz}$ microwave radiation and autonomic nerve stimulation leading to alteration in heart beats, palpitation, flutter, blood pressure, sweating, nausea etc., in individuals vulnerable to electromagnetic frequencies. Havas and colleagues, in a small group of subjects, had observed an immediate and dramatic response after exposure to microwave radiations with a digital cordless phone. They have observed a dramatic increase in the heart rate when exposed to these radiations [4].

The findings of this study have shown a significant decrease in the pulse rate over 14-measurements with the use of Enviro Chip fixed on electronic gadgets of the volunteers. Literatures are replete with evidence showing changes in pulse rate with the use of high-end mobile phones, laptops and personal computers etc., the finding of this study showed that installing Enviro Chip would probably benefit people who cannot avoid or reduce duration of using these electronic gadgets for hours at stretch. We noted that installing Enviro Chip reduced the pulse rate in both genders indicating that Enviro Chip 
may benefit all those using electronic instruments for a prolonged time on a daily basis. A similar unpublished study conducted at the office of a French ITES company-M/s. Steria India Ltd, Noida involving 137 healthy volunteers has also demonstrated reduction in pulse rate over 14 measurements with the use of Enviro Chip. In conjunction with this study, the present study highlights that Enviro Chip has potential to stabilise pulse rate within the normal range and hence predicts potential use as radiation harmonizing device to be used on electronic gadgets such as the mobile phones/computers/laptops.

In summary, the present study has revealed that prolonged use of laptops, personal computers and mobiles poses long-term health implications and the Enviro $\mathrm{Chip}^{\circ}$, has potential to reduce harmful effects from the use of high-end electronic gadgets of the present world. However, this was just a primordial study interpreting conclusively the changes in pulse rate by radiation and hence, effects of Enviro Chip warrant further study, using several other indices of human health and large study population.

\section{ACKNOWLEDGEMENTS}

We acknowledge thanks to Ms. Kalpana for doing the statistical analysis and Mr. Gaurav Bhardwaj for coordinating the study and data management.

\section{REFERENCES}

[1] Hardell, L., Carlberg, M. and Hansson Mild, K. (2006) Pooled analysis of two case-control studies on the use of cellular and cordless telephones and the risk of malignant brain tumors, diagnosed in 1997-2003. International Archives of Occupational and Environmental Health, 79, 630-639. doi:10.1007/s00420-006-0088-5

[2] Hardell, L., Carlberg, M., Söderqvist, F., Mild, K.H. and Morgan, L.L. (2007) Long-term use of cellular phones and brain tumors: Increased risk associated with used for $\geq 10$ years. Occupational and Environmental Medicine, 64, 626-632. doi:10.1136/oem.2006.029751

[3] Khurana, V.G., Teo, C., Kundi, M., Hardell, L. and Carlberg, M. (2009) Cell phones and brain tumors: A review including long-term epidemiological data. Surgical Neurology, 72, 205-215. doi:10.1016/j.surneu.2009.01.019

[4] Havas, M., Marrongelle, J., Pollner, B., Kelley, E., Rees, C.R.G. and Tully, L. (2010) Provocation study using heart rate variability shows microwave radiation from 2.4 $\mathrm{GHz}$ cordless phone affects autonomic nervous system. European Journal of Oncology, 5, 273-291.

[5] Hyland, G.J. (2000) Physics and biology of mobile telephony. Lancet, 356, 1833-1836.

[6] Nageswari, K.S. (1990) biological effects of microwaves: A review. Annals of the National Academy of Medical Sciences (India), 26, 1-16.
[7] Rubin, G.J., Das Munshi, J. and Wessely, S. (2005) Electromagnetic hypersensitivity: A systematic review of provocation studies. Psychosomatic Medicine, 67, 224-232. doi:10.1097/01.psy.0000155664.13300.64

[8] Genuis, S.J. and Lipp, C.T. (2012) Electromagnetic hypersensitivity: Fact or fiction? Science of the Total Environment, 414, 103-112. doi:10.1016/j.scitotenv.2011.11.008

[9] Baan, R., Grosse, Y., Secretan-Lauby, B., El Ghissassi, F., Bouvard, V., Benbrahim-Tallaa, L., et al. (2011) On behalf of the WHO International Agency for Research on Cancer Monograph Working Group. Carcinogenicity of radiofrequency electromagnetic fields. The Lancet Oncology, 7, 624-626. doi:10.1016/S1470-2045(11)70147-4

[10] Litovitz, T.A., Penafiel, L.M., Farrel, J.M., Krause, D., Meister, R. and Mullins, J.M. (1997) Bioeffects induced by exposure to microwaves are mitigated by superposition of ELF noise. Bioelectromagnetics, 18, 422-430. doi:10.1002/(SICI)1521-186X(1997)18:6<422::AID-BE M4>3.0.CO;2-4

[11] Litovitz, T.A., Krause, D., Montrose, C.J. and Mullins, J.M. (1994) Temporally incoherent magnetic fields mitigate the response of biological systems to temporally coherent magnetic fields. Bioelectromagnetics, 15, 399-409. doi:10.1002/bem.2250150504

[12] Ayeni, A.A., Braimoh, K.T. and Ayeni, O.B. (2011) Effect of GSM radiation on human pulse rate (Heart beat rate). Journal of Emerging Trends in Computing and Information Sciences, 2, 580-587.

[13] Kannel, W.B., Kannel, C., Paffenbarger Jr., R.S. and Cupples, L.A. (1987) Heart rate and cardiovascular mortality: The Framingham Study. American Heart Journal, 113, 1489-1494. doi:10.1016/0002-8703(87)90666-1

[14] Gillum, R.F., Makuc, D.M. and Feldman, J.J. (1991) Pulse rate, coronary heart disease, and death: The NHANES I Epidemiologic Follow-up Study. American Heart Journal, 121, 172-177. doi:10.1016/0002-8703(91)90970-S

[15] Shaper, A.G., Wannamethee, G., Macfarlane, P.W. and Walker, M. (1993) Heart rate, ischaemic heart disease, and sudden cardiac death in middle-aged British men. British Heart Journal, 70, 49-55. doi:10.1136/hrt.70.1.49

[16] Arnold, J.M., Fitchett, D.H., Howlett, J.G., Lonn, E.M. and Tardif, J.C. (2008) Resting heart rate: A modifiable prognostic indicator of cardiovascular risk and outcomes? Canadian Journal of Cardiology, 24, 9A-15A.

[17] Andrzejak, R., Poreba, R., Poreba, M., et al. (2008) The influence of the call with a mobile phone on heart rate variability parameters in healthy volunteers. Industrial Health, 46, 409-417. doi:10.2486/indhealth.46.409

[18] Lai, H. and Singh, N.P. (1995) Acute low-intensity microwave exposure increases DNA single-strand breaks in rat brain cells. Bioelectromagnetics, 16, 207-210. doi:10.1002/bem.2250160309

[19] Hardell, L., Mild, K.H. and Carlberg, M. (2003) Further aspects on cellular and cordless telephones and brain tumours. International Journal of Oncology, 22, 399.

[20] Adlkofer, F. (2004) REFLEX, risk evaluation of potential 
environmental hazards from low frequency electromagnetic field exposure using sensitive in vitro methods.

[21] Al-Khlaiwi, T. and Meo, S.A. (2004) Association of mobile phone radiation with fatigue, headache, dizziness, tension, and sleep disturbance in Saudi population. Saudi Medical Journal, 25, 732-736.

[22] Röösli, M., Moser, M., Baldinini, Y., Meier, M. and BraunFahrländer, C. (2004) Symptoms of ill health ascribed to electromagnetic field exposure-A questionnaire survey. International Journal of Hygiene and Environmental Health, 207, 141-50. doi:10.1078/1438-4639-00269

[23] Hardell, L., Carlberg, M. and Hansson Mild, K. (2012) Use of mobile phones and cordless phones is associated with increased risk for glioma and acoustic neuroma. Pathophysiology, EPUB Ahead of Print. doi:10.1016/j.pathophys.2012.11.001 